\title{
SERO DIAGNOSIS OF DENGUE VIRUS INFECTION USING ELISA IN PATIENTS WITH SUSPECTED DENGUE INFECTION
}

Pramod S. Manthalkar ${ }^{1}$, B. V. Peerapur²

\section{HOW TO CITE THIS ARTICLE:}

Pramod S. Manthalkar, B. V. Peerapur. "Sero Diagnosis of Dengue Virus Infection using ELISA in Patients with Suspected Dengue Infection". Journal of Evolution of Medical and Dental Sciences 2015; Vol. 4, Issue 62, August 03; Page: 10824-10828, DOI: 10.14260/jemds/2015/1562

ABSTRACT: AIM: To identify the Seropositivity of dengue virus infection in clinically suspected patients. MATERIAL AND METHODS: A cross sectional study was conducted in north Karnataka from Jan 2012 to August 2013. Clinically suspected patient suffering from dengue virus infection were included in the study according to WHO criteria. Acute phase sera were collected after 5 days of the onset of fever as per WHO criteria. Serology was performed using ELISA for detection of IgG and IgM. A primary dengue infection was defined by a positive IgM ELISA and negative IgG. Secondary infection was defined as positive IgG with or without IgM. RESULTS: Among 580 patient who met the WHO criteria for dengue infection 246(42.41 \%) were ELISA positive among whom 71(28.87\%) had primary infection. Secondary infection was reported in 175(71.13). Acute phase sera of 344 (59.31\%) were negative by ELISA. Thrombocytopenia was evident in 52(71.83\%) with primary infection and $115(65.71 \%)$ patients with secondary dengue infection out of 167 patients who were positive for dengue IgM/IgG antibodies.

KEYWORDS: Dengue, IgG and IgM.

INTRODUCTION: Dengue is a mosquito borne Arboviral infection found in tropical and subtropical regions around the world. Dengue is caused by four distinct viruses type 1 to 4 that are closely related antigenically. Human beings are the main amplifier of the virus. The clinical presentation varies from self-limiting disease to complications like hemorrhage and shock. World Health Organization formulated case classification of dengue into dengue fever (DF)/Dengue hemorrhagic fever (DHF)/dengue shock syndrome (DSS) ${ }^{1,2}$

The first major epidemic illness compatible clinically with dengue occurred in Madras in 1780 in India which later spread to all over the country. All the serotypes have been identified and isolated form Indian patients up till now.3,4,5 Bidar is at the extreme north part of Karnataka state and which has two state boundaries adjacent Maharashtra and Andra Pradesh. Migration of people form one state to another is very common. Epidemic of chickungunya was observed in and around Bidar in 2006 and recently dengue virus infection has become more prevalent.

This study was carried out in Bidar to evaluate the Sero prevalence of dengue virus infection in and around Bidar by ELISA in suspected cases of dengue virus infection. This is the first such type of study to be done on dengue virus infection. We also evaluated the role of ELISA in diagnosis of the dengue virus infection in clinically suspected cases. In dengue epidemic area like Bidar serological evidence is useful to provide information on epidemiology of the disease which can help to take necessary measures to control and prevent Dengue infection.

MATERIALS AND METHODS: The present study is a hospital based cross sectional study conducted in a tertiary care teaching Hospital in Bidar from Jan. 2012 to Aug. 2013. All patients of both genders and all age groups presenting with acute febrile illness, bleeding tendency, leucopenia or thrombo- 


\section{ORIGINAL ARTICLE}

cytopenia were included. Patients with haematological malignancies, bleeding diathesis, cirrhosis, enteric fever and malaria were excluded.

Patients presenting with acute febrile illness along with two or more of the following signs and symptoms were considered in the study such as, headache, retro-orbital pain, Myalgia, arthralgia, rash, hameorrhagic manifestations, leucopenia and supportive serology.

To exclude the possibility of malaria and typhoid fever, peripheral thick and thin smear and blood culture was done respectively in selected cases. Acute phase sera were collected from the patients presenting with fever and more than two complaints as mentioned above from patients attending OPD and admitted in the hospital. The serum samples were subjected for detection of $\operatorname{IgG}$ and IgM anti dengue antibodies by ELISA Kit manufactured by Pan Bio. A primary infection was indicated when the IgM to IgG index value ratio was 1.78 and secondary infection was indicated when the IgM to IgG ratio was less than 1.78. Depending on this criteria patients were categorized as suffering from primary or secondary infections. Data was analyzed by SPSS version 10. Relevant descriptive statistics like frequency, mean and percentage were calculated for presentation of data.

RESULTS: Among 580 patients attending OPD and admitted with suspected dengue, 246 patients were sero positive. Maximum cases were reported in the month of August, September and October. Primary infection was reported in 71cases (28.87\%) and Secondary infection in 175(71.13\%) as shown in the pi diagram. The male to female ratio was 1.2:1. The maximum number of patients presented in the age group 15 to 30years followed by 30 to 45,45 and above, 0 to 50 in decending order.

\begin{tabular}{|c|c|c|c|}
\hline Age in years & Male & Female & Total \\
\hline 0 to 15 & $56(45.16 \%)$ & $68(54.83 \%)$ & $124(21.37 \%)$ \\
\hline 15 to 30 & $136(59.64 \%)$ & $92(40.35 \%)$ & $228(39.31 \%)$ \\
\hline 30 to 45 & $36(31.03 \%)$ & $80(68.96 \%)$ & $116(20 \%)$ \\
\hline 45 to 60 & $64(57.14 \%)$ & $48(42.85 \%)$ & $112(19.31 \%)$ \\
\hline Total & $292(50.34 \%)$ & $288(49.65 \%)$ & 580 \\
\hline
\end{tabular}

Out of the 246 seropositive patients (69)28.04\% were positive for IgM antibodies and (96)39.02\% were positive for IgG antibodies and (81)32.92\% were positive for both IgM and IgG antibodies.

Of the 246 sample positive for dengue antibodies, 109 patients required platelet transfusion due to bleeding tendency or platelet count $<25000$. Nine with primary infection and 100 with secondary infection were transfused.

Three hundred and thirty four (57.58\%) patients with suspected dengue infection were negative for IgG \& IgM antibody by ELISA. Details of the clinical presentation of patients with suspected dengue infection is given in table 2 . 


\section{ORIGINAL ARTICLE}

\begin{tabular}{|c|l|c|}
\hline $\begin{array}{r}\text { Sl. } \\
\text { No. }\end{array}$ & \multicolumn{1}{|c|}{ Signs and Symptoms } & $\begin{array}{c}\text { Percentage } \\
\text { (\%) }\end{array}$ \\
\hline 1. & Fever & 100 \\
\hline 2. & Myalgias & 59 \\
\hline 3. & Arthalgias & 22 \\
\hline 4. & Headache & 81 \\
\hline 5. & Abdominal pain & 28 \\
\hline 6. & Rash & 42 \\
\hline 7. & Mucosal bleeding & 10 \\
\hline 8. & Leucopenia & 5 \\
\hline 9. & Platelet count $<50000 / \mathrm{mm} 3$ & 43 \\
\hline 10. & Platelet count $<1,50,000 / \mathrm{mm} 3$ & 31 \\
\hline 11. & Platelet count $>1,50,000 / \mathrm{mm} 3$ & 26 \\
\hline \multicolumn{2}{|c|}{ Table 2: Percentage wise distribution of patients } \\
\hline \multicolumn{2}{|c|}{ suffering from various symptoms } \\
\hline
\end{tabular}

DISCUSSION: Bidar has got cyclic epidemic of dengue virus infection and most cases are seen during the post monsoon season. Maximum number of cases was observed during the months from August to November, indicating that the propagation of mosquitoes is more in this season and effective pesticide treatment should be done to avoid the communicable diseases.

Majority of the target population were young adults between age group 13 to 35years, males were predominantly infected. Among the clinical signs and symptoms high proportion of febrile syndrome, severe headache, thrombocytopenia, Myalgia and rash were present in patients with Dengue fever.

Laboratory diagnosis for confirmation of dengue fever includes isolation of the virus from serum and detection of dengue virus genome by polymerase chain reaction. ${ }^{3}$ These tests are available in the reference laboratories. Applying these gold standard tests is out of reach in a tertiary care center like ours. In clinical setting diagnosis of dengue infection is primarily based on detecting the dengue specific antibodies in the serum. Four fold rise or reciprocal IgG or IgM antibody titer to one or more dengue virus antigens in the serum is the most important in diagnosis of dengue virus infection.

Immune response is different in primary and secondary dengue infection. In primary infection specific IgM antibodies are seen after 5-6 days of onset of illness and IgG levels after 7-10 days and persist for life at a lower titer (HAI 1:640). During secondary infection high titer of IgG (HAI 1:2,560) appears earlier. IgM antibodies are either present in low titer or absent during secondary infection. $6,7,8,9$

The present study reports dengue antibody positivity rate of $42 \%$. Our finding is supported by 0 P Sah et al. who demonstrated antibody positivity of $50 \%$ in patients of Terai region of Nepal. ${ }^{10}$ In the present study Dengue IgM antibodies was detected higher in the age group 15 to 30 years. Our finding is also supported by Gupta et al ${ }^{11}$ and Rahman et al. ${ }^{12}$

The present study reports that a significant percentage of patients had secondary infection 175/246 (71.13\%). Prior sensitization by heterologous serotypes increased the relative risk of acquiring more severe diseases in secondary than in primary infection. 


\section{ORIGINAL ARTICLE}

In the present study 97 out of 175 patients of secondary dengue infection and 29 out of 71 in primary dengue infection required platelet transfusion.

Thrombocytopenia is often relied upon as important criteria for the diagnosis of dengue infection among the patients presenting with an acute non- specific febrile illness. Out of 580 patients with suspected dengue infections, thrombocytopenia was seen in 429 cases (74\%). Thrombocytopenia was evident in 167 patients (68\%) who were positive for dengue IgM/IgG antibodies. Our study is consistent with Kulkarni et al ${ }^{13}$ who also studied association of dengue parameter positivity with thrombocytopenia and showed that thrombocytopenia was associated excellently when both NS 1 and IgM were positive compared to NS 1 alone. The role of antibody in the pathogenesis of dengue fever is well known. Therefore, better association of platelet count with detection of antibody is consistent. In the absence of thrombocytopenia in patients with suspected dengue infection we should consider other clinical features such as nausea, vomiting, abdominal pain, duration of fever more than three days ${ }^{8}$ and leucopenia before dismissing a case of dengue infection. ${ }^{9}$ These clinical features are significantly associated with acute dengue virus infection. ${ }^{14}$

CONCLUSION: The present study was carried out to identify the primary and secondary dengue infection and to know the sero prevalence of dengue virus infection. We conclude that identification of secondary infection early during an acute phase of illness is valuable for the clinicians due to high risk of life threatening DHF and DSS that can be reduced by early transfusion and supportive therapy. Investigating sero prevalence of dengue virus infections in the community provides an opportunity to investigate the risk factors for transmission, natural history of infection and effectiveness of prevention methodology.

\section{REFERENCES:}

1. World Health Organization. Dengue haemorrhagic fever. Diagnosis, treatment, prevention and control (2 $2^{\text {nd }}$ edition) Chapter 4. World Health Organizatinon: Geneva, 1997.

2. World Health Organization. Dengue haemorrhagic fever. Diagnosis, treatment, prevention and control (2nd edition) Chapter 2. World Health Organizatinon: Geneva, 1997.

3. Lanciotti RS, Calisher CH, Gubler DJ, Chang GJ, Vorndam AV. Rapid detection and typing of dengue viruses from clinical samples by using reverse transcriptase-polymerase chain reaction Journal of clinical Microbiol 1992;30:545-51.

4. Siqueira JB, Martelli CM, Coelho GE, Simplicio AC, Hatch DL. Dengue and dengue Haemorrhagic fever, Brazil, 1981-2002. Emerg Infect Dis 2005; 2: 48-53.

5. World Health Organization, Dengue haemorrhagic fever. Diagnosis, treatment, prevention and control. $2^{\text {nd }}$ ed. Chapter 2. World Health Organization: Geneva, Switzerland; 1997.

6. World Health Organization. World Health Organization. Dengue Bull: Geneva, Switzerland; 2003.p. 27.

7. Wilder-smith A, Schwartz E, Dengue in travelers. N Engl J Med 2005; 353: 924-32.

8. Cao xuan TO, Ngo TN, Rachel $\mathrm{k}$ et al. Clinical diagnosis and assessment of severikty of confirmed Dengue infections in Vietnamese children: Is the World Health Organization classification system helpful? Am. J. Trop. Med. Hyg 2004;70 (2): 172-179

9. Kalayanarooj S, Nimmannitya S, Suntayakorn S et al. Can Doctors Make an Accurate Diagnosis of Dengue Infection at an Early Stage? Dengue Bull 2000; 23: 1-9. 


\section{ORIGINAL ARTICLE}

10. OP Sah, S Subedi, K Morita et al. Serological study of dengue virus infection in Terai region, Nepal: Nepal Med Coll J 2009; 11(2): 104-106.

11. Guptal E, Dar L, Kapoor G, Broor S. The changing epidemiology of dengue in Delhi, India. Virol J 2006; 3: 92.

12. Rahaman M, Rahaman K, Siddque AK et al. First outbreak of dengue hemorrhagic fever, Bangladesh. Emerg Infect Dis 2002; 8: 738-40.

13. RD Kulkarni, SS Patil, GS Ajantha et al. Association of platelet count and serological markers of dengue infection- importance of NS 1 antigen. Indian J Medical Microbiol. 2011; 29(4):359-62.

14. David W. Vaughn, Ananda Nisalak, Tom Solomon et al. Rapid serologic diagnosis of dengue virus infection using a commercial capture ELISA that distinguish primary and secondary infections. Am J. Trop. Med. Hyg., 60(4), 1999, pp.693-698.

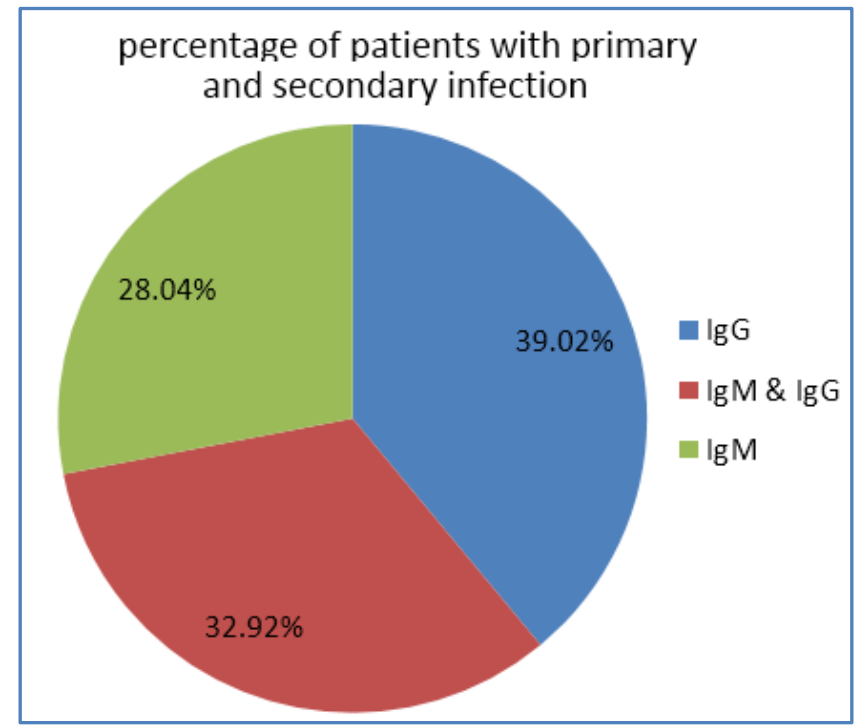

\section{AUTHORS:}

1. Pramod S. Manthalkar

2. B. V. Peerapur

\section{PARTICULARS OF CONTRIBUTORS:}

1. Assistant Professor, Department of Microbiology, BRIMS, Bidar, Karnataka.

2. Professor \& Head, Department of Microbiology, RIMS, Raichur, Karnataka.

FINANCIAL OR OTHER COMPETING INTERESTS: None

\section{NAME ADDRESS EMAIL ID OF THE} CORRESPONDING AUTHOR:

Pramod S. Manthalkar, Assistant Professor, Department of Microbiology, Bidar Institute of Medical Sciences, Bidar-585401, Karnataka.

E-mail: pramodmanthalkar@gmail.com

Date of Submission: 03/07/2015.

Date of Peer Review: 04/07/2015.

Date of Acceptance: 16/07/2015.

Date of Publishing: 01/08/2015. 